\title{
BMJ Open Diagnostic and laboratory test ordering in Northern Portuguese Primary Health Care: a cross-sectional study
}

\author{
Luísa Sá, ${ }^{1,2}$ Andreia Sofia Costa Teixeira, ${ }^{3}$ Fernando Tavares, ${ }^{4}$ \\ Cristina Costa-Santos, ${ }^{1,3}$ Luciana Couto, ${ }^{1}$ Altamiro Costa-Pereira, ${ }^{1,3}$ \\ Alberto Pinto Hespanhol, , ${ }^{1,3}$ Paulo Santos, ${ }^{1,3}$ Carlos Martins ${ }^{1,3}$
}

To cite: Sá L, Teixeira ASC, Tavares F, et al. Diagnostic and laboratory test ordering in Northern Portuguese Primary Health Care: a crosssectional study. BMJ Open 2017;7:e018509. doi:10.1136/ bmjopen-2017-018509

- Prepublication history for this paper is available online. To view these files, please visit the journal online (http://dx.doi. org/10.1136/bmjopen-2017018509).

Received 5 July 2017 Revised 11 September 2017 Accepted 3 October 2017

\section{CrossMark}

${ }^{1}$ MEDCIDS—Department of Community Medicine, Information and Health Decision Sciences, Faculty of Medicine, University of Porto, Porto, Portugal

${ }^{2}$ Family Health Unit Nova Via, Porto, Portugal

${ }^{3}$ Centre for Research in Health Technologies and Information Systems (CINTESIS), Faculty of Medicine, University of Porto, Porto, Portugal

${ }^{4}$ Department of Studies and Planning, Northern Regional Health Administration, Porto, Portugal

Correspondence to

Professor Luísa Sá;

luisa.de.sa@gmail.com

\section{ABSTRACT}

Objectives To characterise the test ordering pattern in Northern Portugal and to investigate the influence of context-related factors, analysing the test ordered at the level of geographical groups of family physicians and at the level of different healthcare organisations.

Design Cross-sectional study.

Setting Northern Primary Health Care, Portugal.

Participants Records about diagnostic and laboratory tests ordered from 2035 family physicians working at the Northern Regional Health Administration, who served approximately 3.5 million Portuguese patients, in 2014.

Outcomes To determine the 20 most ordered diagnostic and laboratory tests in the Northern Regional Health Administration; to identify the presence and extent of variations in the 20 most ordered diagnostic and laboratory tests between the Groups of Primary Care Centres and between health units; and to study factors that may explain these variations.

Results The 20 most ordered diagnostic and laboratory tests almost entirely comprise laboratory tests and account for $70.9 \%$ of the total tests requested. We can trace a major pattern of test ordering for haemogram, glucose, lipid profile, creatinine and urinalysis. There was a significant difference $(P<0.001)$ in test orders for all tests between Groups of Primary Care Centres and for all tests, except glycated haemoglobin $(\mathrm{P}=0.06)$, between health units. Generally, the Personalised Healthcare Units ordered more than Family Health Units.

Conclusions The results from this study show that the most commonly ordered tests in Portugal are laboratory tests, that there is a tendency for overtesting and that there is a large variability in diagnostic and laboratory test ordering in different geographical and organisational Portuguese primary care practices, suggesting that there may be considerable potential for the rationalisation of test ordering. The existence of Family Health Units seems to be a strong determinant in decreasing test ordering by Portuguese family physicians. Approaches to ensuring more rational testing are needed.

\section{INTRODUCTION}

Evidence revealed excessive requests for diagnostic and laboratory tests by the various providers of healthcare services, including Primary Health Care. ${ }^{1}$ The most frequent

\section{Strengths and limitations of this study}

- A cross-sectional study where approximately 24.5 million ordered tests were analysed, from 2035 Family Physicians and 3.5 million patients, with detailed information about the 20 most ordered diagnostic and laboratory tests. The ordered test data were extracted directly from a national and official database, so there is no selection bias or dependence on response rates.

- The significant and large variability in diagnostic and laboratory test ordering in different geographical and organisational Portuguese primary care practices suggests a tendency for overtesting and a considerable potential for the rationalisation of test ordering.

- The major differences observed seem to reflect an organisation-related factor. The existence of Family Health Units, a new health unit organisation in Portuguese Primary Care, seems to be a strong determinant in decreasing test order.

- However, these results should be interpreted with caution because we are unaware of the reason for the test ordering.

errors in test ordering are the use of routines and sometimes inappropriate diagnostic and laboratory tests, with an increasing number of test requests for healthy people when the evidence recommends only a very restricted screening test panel. ${ }^{2-4}$

In 2014, Portugal spent about $9.0 \%$ of its gross domestic product on healthcare costs. ${ }^{5}$ Per capita, Portugal spends about 2584 US dollars a year on healthcare, about $50 \%$ more than 15 years ago. ${ }^{5}$ However, per capita, Portugal spends less than the average of the Organisation for Economic Co-operation and Development member countries. ${ }^{56}$

According to the 2009/2010 Activity Report of the Central Administration of the Health Service, diagnostic and laboratory tests in ambulatory care constituted a significant proportion of total health expenses and 
represented about $8 \%$ of the Portuguese National Health System expenses. The most representative entities are, in terms of costs, the units of Primary Health Care. Laboratory tests are the most ordered, followed by physical medicine and rehabilitation treatments and radiological tests. In terms of costs, the largest share of spending is for laboratory tests, followed by radiological tests and physical medicine and rehabilitation. ${ }^{7}$

In Portugal, the vast majority of the adult population considers that many medical tests are necessary on a nearly annual basis, and most of the patients say that they received those tests. ${ }^{3}$ These data show the tendency to overuse the health services. Many of these tests may cause healthy people to become unhealthy, cause iatrogenic illnesses and waste precious resources. ${ }^{49}$ Most tests may cause confusion, anxiety and unnecessary medical consultations and lead to a cascade of other tests and unnecessary medical procedures.

Providing citizens with the best available healthcare is ethically imperative. The principle of justice, in the context of a situation where resources are limited, leads to the need for rational allocation of available resources, reconciling the beneficence principle of medical practice with constraints resulting from an adverse situation. ${ }^{6}$

Studying the use of diagnostic and laboratory tests is a way to control quality of test ordering so that the level of health services provided can be maintained. Family physicians are important gatekeepers in terms of identification of patients who need further testing and referral. Testing should always be appropriate to make this decision. ${ }^{10}$

A wide variation in test ordering practice has been shown, ${ }^{11-15}$ and the recent restructuring of Primary Health Care in Portugal may contribute to this variability. ${ }^{16}$ Studies to compare ordering behaviour is a way to obtain useful information for optimising diagnostic and laboratory test requests, ${ }^{15} 1718$ and baseline practice must be measured to establish if and where changes are needed.

The present study attempted to characterise the test ordering pattern in Northern Portugal and to investigate the influence of context-related factors, analysing the test ordered at the level of geographical groups of family physicians and at the level of different healthcare organisations.

The objectives of this study are to determine the 20 most ordered diagnostic and laboratory tests in the Northern Regional Health Administration; to identify the presence and extent of variations in the 20 most ordered diagnostic and laboratory tests between the Groups of Primary Care Centres and between health units; and to study factors that may explain these variations.

\section{MATERIALS AND METHODS Study design}

A cross-sectional study was conducted, using diagnostic and laboratory test ordered data obtained from a clinical information system called the Regional Health Administration Information System (SIARS). ${ }^{19}$

\section{Setting}

The Portuguese National Health Service is a large healthcare organisation that serves more than 10 million beneficiaries and contains a strong core of family physicians. ${ }^{20}$ The Portuguese National Health System is administratively divided into five Regional Health Administrations (Northern, Centre, Lisbon and Tagus Valley, Alentejo and Algarve). Each Regional Health Administration is divided into Groups of Primary Care Centres (ACES). The Groups of Primary Care Centres are health services with administrative autonomy, made up of several functional units of Primary Health Care, individualised by specific location and denomination, that function to provide primary healthcare to a specific geographical area. Each Group of Primary Care Centres is composed of a group of Health Units, formed by small multiprofessional teams. There are two types of health unit organisations: Family Health Units and Personalised Healthcare Units. The creation of the Family Health Units were the main focus of the transformation of Portuguese Primary Care in 2007. ${ }^{161}$ They are professional cohesive teams, combining principles of decentralisation, self-organisation and accountability for the results achieved. ${ }^{16}$ The Family Health Unit B model includes remuneration return linked to the professionals' performance, which has two components: supplements associated with the amount of work required (number of patients per family physician) and supplements linked to compliance with certain indicators. The Family Health Unit A model can be regarded as the stage before progression to the B model, and there is no return linked to the professionals' performance. Adherence to Family Health Unit model is a voluntary process; thus, teams of traditional primary healthcare units who did not adhere to Family Health Unit model continue to work on the called Personalised Healthcare Units. In these teams, there is also no pay per performance.

We used the diagnostic and laboratory test ordering data from Northern Regional Health Administration from the year 2014, obtained at the physician level and then aggregated by health unit and Groups of Primary Care Centres. These data include the following test areas: laboratory tests, radiological tests, physical medicine and rehabilitation treatments, cardiology tests, gastroenterology tests, pathologic anatomy tests, pneumology and immunoallergology tests, nuclear medicine tests, electroencephalography tests, neurophysiology tests, otorhinolaryngology tests and some specific medical consultations or others (as psychology tests, for instance). ${ }^{7}$

\section{Selection criteria}

All family physicians working in the Northern Regional Health Administration were included. All the 24 Groups of Primary Care Centres (coded alphabetically) and the 379 health units (149 Personalised Healthcare Units, 119 Family Health Unit A model and 111 Family Health Unit 
B model) belonging to this Regional Health Administration were included. The patients studied represented more than one-third of the Portuguese population.

\section{Variables and instruments}

The diagnostic and laboratory test ordered data were obtained from a clinical information system called SIARS, which is a repository of data from all health units in Portuguese primary care. ${ }^{19}$

The study variables were diagnostic and laboratory tests ordered, Groups of Primary Care Centres, health units, patients' number, patients' age, consultations' number, family physicians' number and number of patients per family physician.

To focus on the most common and in tests that are economically significant, the analysis was limited to the 20 diagnostic and laboratory tests most ordered.

\section{Statistical analysis}

Statistical analysis was performed using the Statistical Package for the Social Sciences V.22.0 for Windows.

To evaluate if there were differences between the Groups of Primary Care Centres and health units, the Kruskal-Wallis test and the respective 95\% CIs for the medians were performed for each exam.

The correlation between the number of requested tests per 1000 patients in each Groups of Primary Care Centres and percentage of elderly users, average of consultations per year, number of patients per family physician and percentage of patients in Family Health Units was calculated using the Spearman rank correlation coefficient.

In all analysis, a $\mathrm{P}<0.05$ was considered significant.

\section{Ethical considerations}

This study was approved by the Northern Regional Health Administration Ethics Committee for Health. Written consent was dispensed because there was no direct contact with the participants, neither patients nor physicians. SIARS database was consulted retrospectively without patients' or family physicians' identification.

\section{RESULTS}

\section{Practice characteristics}

Approximately 11.5 million consultations and 24.5 million ordered tests were analysed, from 2035 Family Physicians and 3453167 patients, as shown in table 1 .

We found that $80 \%$ of the Northern Regional Health Administration patients had at least one consultation in 2014 (called 'user patient'), and of these patients, $65.5 \%$ had at least one test requested. There was a mean of 7.3 tests ordered per patient, 8.9 tests per 'user patient' and approximately 13.7 tests per patient that had tests requested. There was a mean of 3.4 consultations per patient and a mean of 4.2 consultations per 'user patient' in 2014, which indicates that there were more than two tests ordered per consultation (table 1).

\section{Test ordering pattern}

The 20 most ordered diagnostic and laboratory tests account for $70.9 \%$ of the total tests requested in Northern Regional Health Administration in 2014. They are comprised almost entirely of laboratory tests, with the exception of the ECG (figure 1).

Of the 20 most ordered diagnostic and laboratory tests in 2014, 5.1 tests were requested per patient, 6.3 tests were requested per 'user patient', and 1.5 tests were requested per consultation (figure 1 and table 1). Independent of the patient's characteristics or risk, we can trace the major pattern of test ordering as follows: haemogram, glucose, total cholesterol, high-density lipoprotein cholesterol, triglycerides, creatinine and urinalysis. This pattern represents about $40 \%$ of the 20 most ordered diagnostic and laboratory tests.

\section{Test ordering variation between groups of primary care centres and explanatory factors}

For variations in Groups of Primary Care Centres, there was a significant difference $(\mathrm{P}<0.001)$ in test ordered for all tests requested per patient (figure 2). However, the greater differences were observed for hepatic function (aspartate aminotransferase (AST), alanine aminotransferase (ALT) and gamma-glutamyl transferase (GGT)), uric acid, urea, erythrocyte sedimentation rate (ESR) and urinalysis. Family physicians in some Groups of Primary Care Centres ordered tests such as ESR and urea at a rate of more than eight and nine times, respectively, that of the Northern Regional Health Administration median. These major differences are common to C, D, E, F and G Groups of Primary Care Centres, and they are less common to S, W and X Groups of Primary Care Centres (figure 2).

Comparing the data with more homogeneous test ordering, we found tests that are frequently used in the diagnosis or follow-up of prevalent chronic diseases in primary care and in colorectal cancer screening, like glucose, lipid profile, creatinine, glycated haemoglobin, microalbuminuria and faecal occult blood test (FOBT). However, we also found tests with fewer recommendations such as haemogram, thyroid-stimulating hormone (TSH), urine culture and ECG (figure 2).

To investigate the relationship between variations in test ordering between Groups of Primary Care and factors potentially affecting tests ordered, we used the Spearman rank correlation coefficient method. The number of tests per 1000 patients, in 2014, varied from 5800 to 10216 , and the mean was 7252 tests. The groups with the highest test ordering were the D, E and G Groups of Primary Care Centres (table 2).

The percentage of the population aged 65 years or older $\left(\mathrm{r}_{\mathrm{s}}=0.55, \mathrm{P}=0.005\right)$ and the number of consultations per year $\left(\mathrm{r}_{\mathrm{s}}=0.48, \mathrm{P}=0.017\right)$ show a positive and statistically significant correlation with the number of tests ordered per 1000 patients. There was a negative correlation between the number of tests ordered per 1000 patients and the percentage of patients in Family Health 


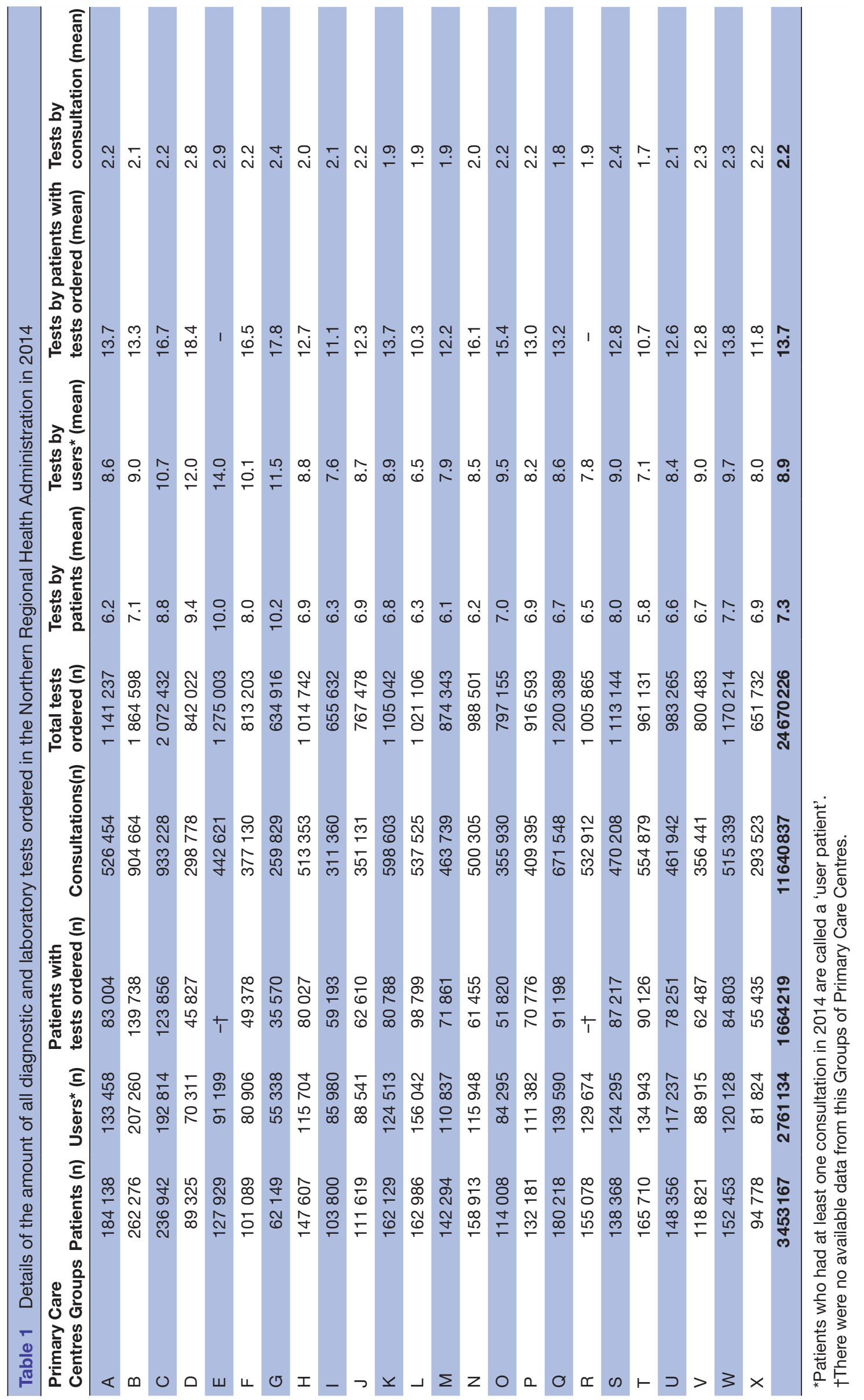




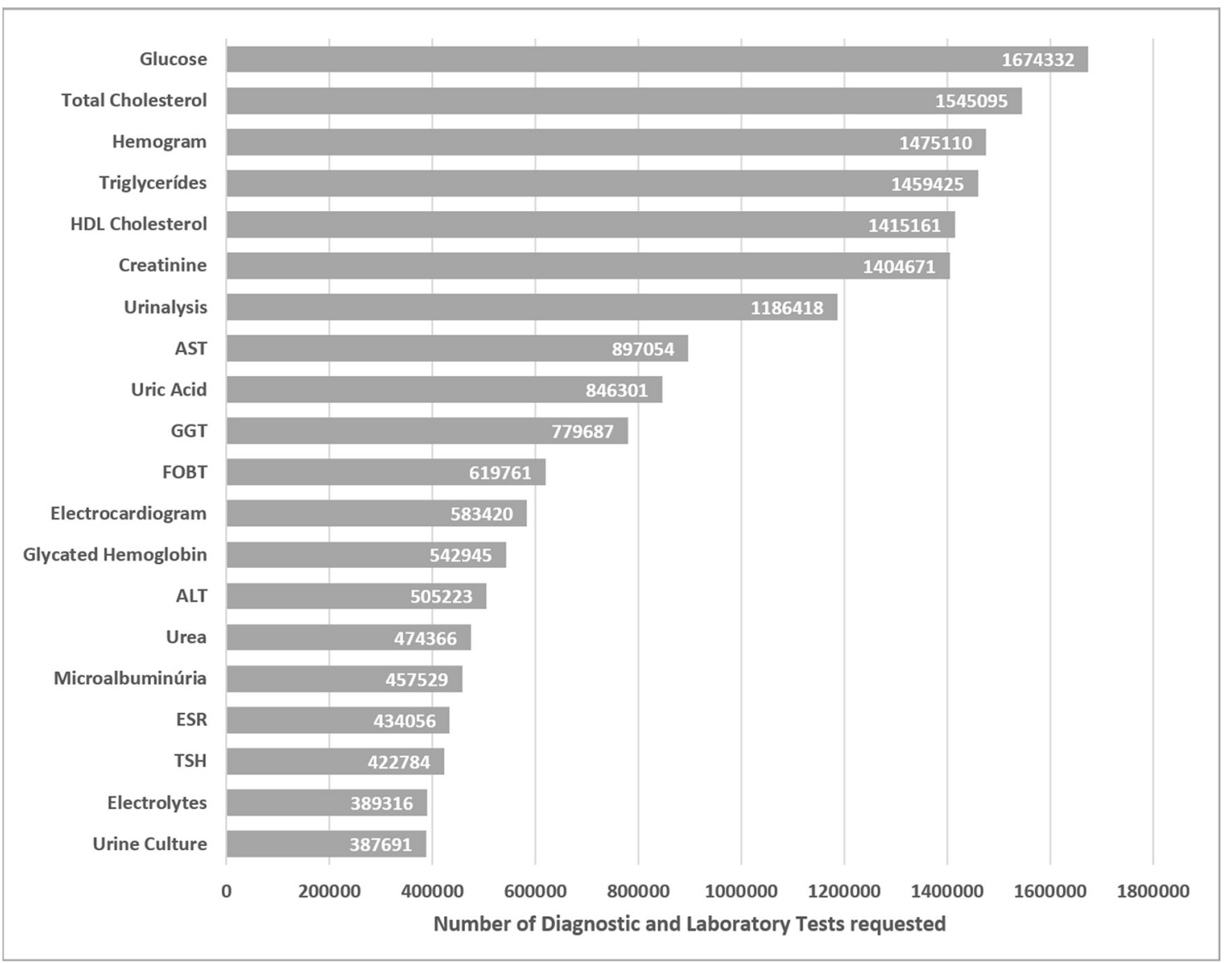

Figure 1 The 20 most ordered diagnostic and laboratory tests in the North Regional Health Administration database in 2014. ALT, alanine aminotransferase; AST, aspartate aminotransferase; ESR, erythrocyte sedimentation rate; FOBT, fecal occult blood test; GGT, gamma-glutamyl transferase; TSH, thyroid-stimulating hormone.

Unit $\left(\mathrm{r}_{\mathrm{s}}=-0.75, \mathrm{P} \leq 0.001\right)$ and the number of patients per family physician $\left(\mathrm{r}_{\mathrm{s}}=-0.55, \mathrm{P}=0.005\right)$, which was statistically significant.

\section{Test ordering variation between health units}

To investigate the variations in test ordering and the different primary care health unit models, we also studied the differences in the 20 most ordered diagnostic and laboratory tests. There was a significant difference $(\mathrm{P}<0.001)$ among health units for all the tests, except for glycated haemoglobin $(\mathrm{P}=0.06)$. Generally, the Personalised Healthcare Units ordered more tests than the Family Health Units (A and B models) (table 3).

The Personalised Healthcare Units ordered more of all the tests than the Family Health Units, with two exceptions: FOBT and microalbuminuria. The highest difference in test ordered is for hepatic function (AST, ALT and GGT), uric acid, urea, sedimentation rate and urinalysis tests. Family physicians in some Personalised Healthcare Units requested tests such as urea and ESR at a rate that was more than four and six times, respectively, that of the Northern Regional Health Administration median (table 3). This pattern is similar to Groups of Primary Care Centres differences, which suggest that these tests are being ordered mostly in the Personalised Healthcare Units of each Groups of Primary Care Centres.
Family Health Unit B model ordered slightly less tests than the Family Health Unit A model. The major differences for these two types of Family Health Units are the less request of AST and GGT tests (table 3).

\section{DISCUSSION}

The 20 most ordered diagnostic and laboratory tests in the Northern Regional Health Administration show a test ordering pattern with a clear predominance of laboratory tests in Portuguese Primary Health Care. A similar pattern was found in test ordering in other general practice studies, ${ }^{1518}$ and the Eurosentinel Study Group showed that haemogram and glucose were the most frequently requested laboratory tests in eight countries. ${ }^{1}$ These results are consistent with the expectations of Portuguese patients, who consider that 'routine blood and urine tests' are the most important preventive medical activities ${ }^{22}$ with a mean frequency interval of 12 months. ${ }^{3}$ This test is popular among Portuguese people in their periodic health examinations or routine health check-ups. ${ }^{22}$

Our results may indicate test overuse because more than six tests of the 20 most ordered diagnostic and laboratory tests were requested, per 'user patient', in lyear, and they constitute $80 \%$ of the total patients. 

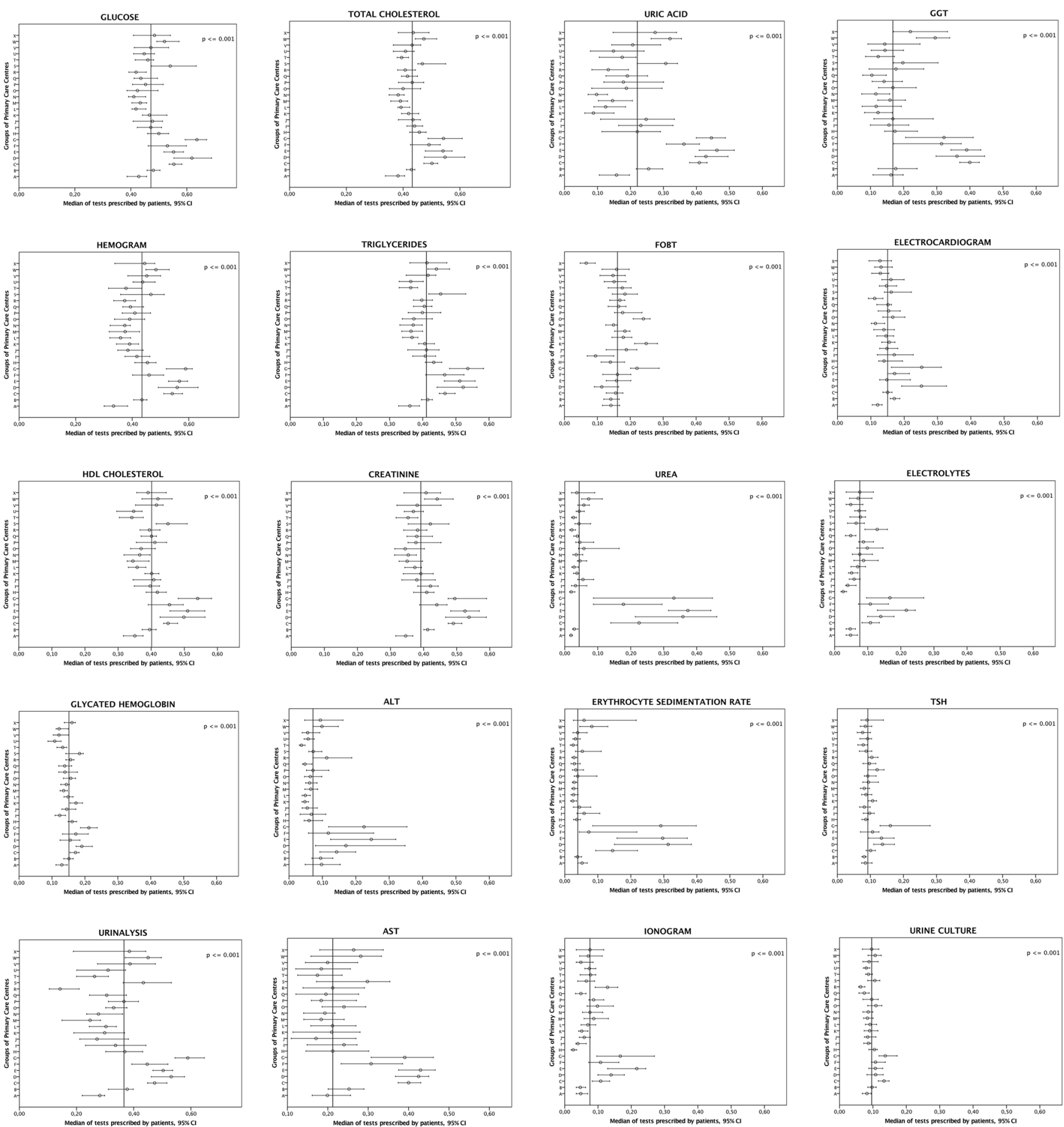

Figure 2 The 20 most ordered diagnostic and laboratory tests by Groups of Primary Care Centres and by patient. ${ }^{*}$ ALT, alanine aminotransferase; AST, aspartate aminotransferase; ESR, erythrocyte sedimentation rate; FOBT, fecal occult blood test; GGT, gamma-glutamyl transferase; TSH, thyroid-stimulating hormone. ${ }^{*}$ The Kruskal Wallis test was used. Medians and respective $95 \% \mathrm{Cl}$ were presented.

Other studies show lower values, and the Eurosentinel Study Group showed a mean of 1.6 to 4.1 tests per 'user patient' (4.1 in Portugal). ${ }^{18}$ We think that some of these data were appropriately requested to monitor chronic diseases and colorectal cancer screening, which is increasingly performed by family physicians, such as lipid and glycaemic profile, creatinine, microalbuminuria and
FOBT. ${ }^{12} 18$ However, others may reflect an inappropriate and overuse of testing. For example, uric acid is a controversial request, and despite evidence to the contrary, most believe that an annual physical examination detects subclinical illness, like metabolic syndrome or gout. ${ }^{1523}$ In some cases, urea and creatinine requests were similar; however, there is evidence indicating that serum urea 
Table 2 Study sample characteristics for all diagnostic and laboratory tests ordered*

\begin{tabular}{|c|c|c|c|c|c|}
\hline $\begin{array}{l}\text { Groups of Primary } \\
\text { Care Centres }\end{array}$ & Tests/1000† & $\% \geq 65$ years $\ddagger$ & $\begin{array}{l}\text { Consultations per } \\
\text { year§ }\end{array}$ & $\begin{array}{l}\text { Number of patients } \\
\text { per family physicianๆl }\end{array}$ & $\begin{array}{l}\text { Patients in Family } \\
\text { Health Units (\%) }\end{array}$ \\
\hline A & 6198 & 15.6 & 2.9 & 1754 & 74.5 \\
\hline B & 7109 & 16.3 & 3.5 & 1821 & 88.0 \\
\hline $\mathrm{C}$ & 8747 & 24.7 & 3.9 & 1481 & 54.2 \\
\hline $\mathrm{D}$ & 9427 & 29.9 & 3.3 & 1540 & 8.8 \\
\hline E & 9967 & 29.7 & 3.5 & 1421 & 0.00 \\
\hline $\mathrm{F}$ & 8044 & 22.4 & 3.7 & 1630 & 41.2 \\
\hline$G$ & 10216 & 23.5 & 4.2 & 1680 & 34.5 \\
\hline $\mathrm{H}$ & 6875 & 18.3 & 3.5 & 1716 & 66.5 \\
\hline 1 & 6316 & 20.2 & 3.0 & 1790 & 74.6 \\
\hline J & 6876 & 19.1 & 3.2 & 1744 & 89.6 \\
\hline K & 6816 & 18.4 & 3.7 & 1725 & 98.2 \\
\hline L & 6265 & 17.0 & 3.3 & 1734 & 87.4 \\
\hline M & 6145 & 17.0 & 3.3 & 1801 & 100.0 \\
\hline $\mathrm{N}$ & 6220 & 21.0 & 3.2 & 1638 & 75.9 \\
\hline 0 & 6992 & 23.6 & 3.1 & 1702 & 68.1 \\
\hline $\mathrm{P}$ & 6934 & 18.8 & 3.1 & 1739 & 71.5 \\
\hline Q & 6661 & 19.0 & 3.7 & 1733 & 73.8 \\
\hline $\mathrm{R}$ & 6486 & 19.3 & 3.4 & 1668 & 85.3 \\
\hline$S$ & 8045 & 18.0 & 3.4 & 1667 & 31.7 \\
\hline $\mathrm{T}$ & 5800 & 13.9 & 3.4 & 1821 & 88.4 \\
\hline$U$ & 6628 & 13.8 & 3.1 & 1766 & 74.8 \\
\hline V & 6737 & 16.7 & 3.0 & 1722 & 76.7 \\
\hline W & 7676 & 16.1 & 3.4 & 1815 & 74.3 \\
\hline$x$ & 6876 & 20.1 & 3.1 & 1692 & 62.4 \\
\hline$r_{s}$ & - & 0.55 & 0.48 & -0.55 & -0.75 \\
\hline$P$ value & - & 0.005 & 0.017 & 0.005 & $\leq 0.001$ \\
\hline
\end{tabular}

*The investigated variables are presented along with their respective Spearman rank correlation coefficient.

†The number of tests ordered per 1000 patients.

$\ddagger$ The percentage of population aged $\geq 65$ years.

$\S$ The mean number of consultations with a family physician per patient in 2014 .

१The mean number of patients per family physician.

provides little more information than serum creatinine alone. $^{24}$

The mean of tests ordered was 7252 per 1000 patients. This value proved to be much higher than other similar studies, like for example in Sweden (2445 tests per 1000 patients) ${ }^{17}$ or in the UK (2964 tests per 1000 patients). ${ }^{18}$ However, these results should be interpreted with caution because of the heterogeneity of the tests included. For example, in some studies, urine dipstick and pregnancy test strip were included, which did not happen in our study. Another example is physical medicine and rehabilitation treatments that were included in our study.

\section{Explaining test ordering variation}

The other important conclusion from our study is the large geographical (Groups of Primary Care Centres) and organisational (health units) differences in test ordering, which are extensively described in literature. ${ }^{11-15} 25$

The major differences observed in some test ordering seem to reflect an organisation-related factor because there are far fewer requests in the Family Health Units compared with the traditional Personalised Healthcare Units. Our study shows a tendency for less request of the 20 most ordered tests in Groups of Primary Care Centres that have a greater percentage of patients in Family Health Units, suggesting that working in Family Health Units rather than according to family physician or geographical preferences may drive Groups of Primary Care Centres variation. Furthermore, when we consider the totality of the ordered tests, a strong negative correlation was found, showing that the greater the percentage of patients in Family Health Units, the less tests are ordered. 
Table 3 The 20 most ordered diagnostic and laboratory tests by health unit, patient and consultation

\section{Median of tests per patient}

(IQR)

\begin{tabular}{|c|c|c|c|c|}
\hline \multirow[b]{2}{*}{ Diagnostic and laboratory tests } & \\
\hline & $\begin{array}{l}\text { Personalised } \\
\text { Healthcare Units }\end{array}$ & $\begin{array}{l}\text { Family Health Units } \\
\text { A model }\end{array}$ & $\begin{array}{l}\text { Family Health Units } \\
\text { B model }\end{array}$ & P-value* \\
\hline Glucose & $0.53(0.44-0.65)$ & $0.46(0.33-0.57)$ & $0.46(0.37-0.55)$ & $\leq 0.001$ \\
\hline Total cholesterol & $0.48(0.40-0.59)$ & $0.41(0.32-0.52)$ & $0.42(0.35-0.49)$ & $\leq 0.001$ \\
\hline Haemogram & $0.50(0.40-0.60)$ & $0.39(0.24-0.52)$ & $0.39(0.28-0.49)$ & $\leq 0.001$ \\
\hline Triglycerides & $0.46(0.37-0.56)$ & $0.40(0.30-0.49)$ & $0.40(0.32-0.47)$ & $\leq 0.001$ \\
\hline Creatinine & $0.46(0.36-0.56)$ & $0.37(0.27-0.47)$ & $0.39(0.31-0.47)$ & $\leq 0.001$ \\
\hline HDL cholesterol & $0.44(0.33-0.55)$ & $0.38(0.28-0.49)$ & $0.38(0.31-0.47)$ & $\leq 0.001$ \\
\hline Urinalysis & $0.48(0.36-0.58)$ & $0.29(0.10-0.46)$ & $0.29(0.13-0.42)$ & $\leq 0.001$ \\
\hline AST & $0.36(0.20-0.47)$ & $0.23(0.09-0.36)$ & $0.17(0.08-0.32)$ & $\leq 0.001$ \\
\hline Uric acid & $0.38(0.25-0.49)$ & $0.16(0.04-0.33)$ & $0.15(0.06-0.31)$ & $\leq 0.001$ \\
\hline GGT & $0.33(0.15-0.45)$ & $0.17(0.06-0.32)$ & $0.13(0.06-0.28)$ & $\leq 0.001$ \\
\hline FOBT & $0.13(0.05-0.25)$ & $0.18(0.11-0.26)$ & $0.17(0.10-0.24)$ & $\leq 0.001$ \\
\hline ECG & $0.16(0.10-0.26)$ & $0.15(0.09-0.22)$ & $0.14(0.09-0.20)$ & $\leq 0.001$ \\
\hline Glycated haemoglobin & $0.15(0.10-0.22)$ & $0.15(0.11-0.19)$ & $0.15(0.11-0.19)$ & 0.060 \\
\hline ALT & $0.15(0.05-0.36)$ & $0.07(0.03-0.18)$ & $0.06(0.03-0.14)$ & $\leq 0.001$ \\
\hline Urea & $0.18(0.04-0.42)$ & $0.04(0.01-0.13)$ & $0.03(0.02-0.07)$ & $\leq 0.001$ \\
\hline ESR & $0.19(0.04-0.40)$ & $0.03(0.01-0.10)$ & $0.03(0.02-0.08)$ & $\leq 0.001$ \\
\hline Microalbuminuria & $0.09(0.05-0.16)$ & $0.14(0.09-0.20)$ & $0.13(0.07-0.19)$ & $\leq 0.001$ \\
\hline TSH & $0.11(0.06-0.20)$ & $0.09(0.06-0.15)$ & $0.09(0.06-0.13)$ & $\leq 0.001$ \\
\hline Urine culture & $0.11(0.07-0.17)$ & $0.09(0.05-0.13)$ & $0.09(0.06-0.13)$ & $\leq 0.001$ \\
\hline Electrolytes & $0.09(0.04-0.22)$ & $0.08(0.03-0.16)$ & $0.06(0.03-0.13)$ & $\leq 0.001$ \\
\hline
\end{tabular}

*The Kruskal-Wallis test was used. Medians and respective 95\% Cls are presented.

ALT, alanine aminotransferase; AST, aspartate aminotransferase; ESR, erythrocyte sedimentation rate; FOBT, faecal occult blood test; GGT, gamma-glutamyl transferase; HDL, high-density lipoprotein; TSH, thyroid-stimulating hormone.

Literature suggests that family physicians who work in group practices ordered fewer tests. ${ }^{11} 12{ }^{26}$ Although all the Portuguese primary care health units are mostly group practices, the new organisation in Family Health Units allowed that small multiprofessional teams with an average of 5-8 family physicians, $6-10$ family health nurses and clinical secretaries, that work together joined on a voluntary basis. These units are characterised by organisational, functional and technical autonomy, with predetermined objectives and targets, in the area of accessibility, quality, outcomes and cost-effectiveness indicators. ${ }^{27}$ The peer review in these professional teams results from general discussions and reflections on practice behaviour and may have the power to modulate requests for tests, improve appropriateness and target available resources more effectively.121328 29 This may justify the reduction of the apparently excessive use of some tests by specific practices, with associated cost savings (in this study, this was the case for hepatic function, uric acid, urea, ESR and urinalysis), although in others the need might be to encourage increased use of underused tests by some practices (such as for FOBT and microalbuminuria).

Several studies have shown a significant decrease in test ordering after physicians were provided with information about test costs. ${ }^{30-35}$ One of the indicators by which Family Health Units are evaluated is the 'average cost of complementary diagnostic and therapeutic requested by user', which provides feedback to family physicians about their resource use and sets annual targets to lower costs. ${ }^{36}$ That may also have contributed to this reduction in test ordering.

The consistency with which some tests are used in the present study, such as haemogram, TSH and urine culture, may be a result of widespread individual or local practice or a request for screening purposes. ${ }^{131517}$ Although Portuguese clinical guidelines discourage routine requests, ${ }^{37-39}$ the Portuguese family physicians' adherence seems to be low, as studies have suggested. ${ }^{6} 40$

In our study, the patients' age distribution (greater than 65 years old) showed a positive correlation with test ordering, meaning that tests in Portugal are requested more often in older patients. This finding is not unanimous because other studies do not find a clear relationship between this variable and test ordering. ${ }^{13} 1517$ The Eurosentinel Study Group studies have reported that the highest number of laboratory tests is ordered for patients between 25 and 64 years of age. ${ }^{1}$ 
A higher workload, such as more consultations per patient and more patients per family physician, has sometimes been highlighted as a contributing factor for a higher test ordering. ${ }^{141} 42$ In fact, our study shows that tests are ordered more often with increasing number of consultations. In opposite, having more patients per family physician was related to less request of tests. In this study, one of the explanation may be that the majority of the patients in the Northern Regional Health Administration (70\%) are in Family Units and they tend to have family physicians with bigger panel sizes. However, we think that this topic has to be investigated considering the individual family physician test ordering and respective panel size in a future research.

\section{Implications for practice and research}

Variations in clinical practice are an important determinant in family physicians' diagnostic and laboratory test ordering. ${ }^{43}$ Given the considerable geographic and organisational variations found in our study, if there was an optimisation/homogenisation of the test ordering, a large cost savings could be achieved. The potential savings in the investigated regions could not be underestimated because the 20 tests studied constitute a high volume of the total tests ordered in Portuguese primary care. Optimised use of laboratory tests will also have effects beyond the direct laboratory cost savings. ${ }^{17}$ As inappropriate test ordering decrease, higher-quality diagnostic information would be obtained so that unexpected results and false-positives would decrease and, concomitantly, so would the number of diagnostic tests performed and consultations required. ${ }^{1517}$

It is unclear whether this variation reflects overtesting in regions of high use or, conversely, failure to provide effective care in regions of low use. It is also unclear to what extent such variation is related to clinical outcomes. ${ }^{1825}$ These results should be interpreted with caution because we are unaware of the reason for ordering these tests. However, the exploration of these variations in test use may help identify priorities for future research.

The present findings, similar to other studies, ${ }^{17} 18$ highlight the need for research on the appropriate use of laboratory tests in primary care, at the level of both practices and organisations.

Perhaps the existing guidelines should be more disseminated in Portuguese primary care to achieve optimised test use. For example, the existing clinical management guidelines for chronic conditions, like diabetes and thyroid disease, both of which require laboratory testing for diagnosis and monitoring, should help to promote harmonisation and reduce variability in practice. ${ }^{1725384445}$ The available guidelines should be about tests with relatively strong evidence, with a better definition of the patient subgroups that should be tested, the optimal interval between screening or monitoring tests and the optimal duration of monitoring; vague guideline recommendations may continue to foster the large increases in test use. ${ }^{17}$
Other approaches to ensuring more appropriate testing might include continuous medical education, electronic order systems with decision support, incentives and audits of family physicians on their request rates and tests costs. ${ }^{14} 1523253646$ In the Portuguese health organisation, the medical coordinators of Groups of Primary Care Centres and health units could provide the feedback on test ordering and adopt a leadership position in this discussion. Optimisation of diagnostic test ordering and promotion of appropriate use may require multifaceted intervention, which should also include better information for the patient.

\section{Strengths and limitations}

One of the strengths of this study is that test ordering data were extracted directly from the Northern SIARS database. The results are not subject to selection bias or dependent on response rates because they include all available data in Northern Regional Health Administration in 2014. Another strength is the sample size, which included more than one-third of patients in the Portuguese National Health Service.

Studies to evaluate medical activities are a tool that is increasingly used to compare performance between organisations using the same measures and the same measurement system. ${ }^{15}$ There are official statistics on diagnostic and laboratory test ordering in Portugal but no studies with this level of information and detail, and to the authors' knowledge, this is the first study of this kind in the Portuguese primary care system.

\section{CONCLUSION}

The results from this study show that the most commonly ordered tests in Portugal are laboratory tests, that there is a tendency for overtesting and that there is a large variability in diagnostic and laboratory test ordered in different geographical and organisational Portuguese primary care practices, suggesting that there may be considerable potential for the rationalisation of test ordering. The existence of Family Health Units seems to be a strong determinant in decreasing test orders by Portuguese family physicians. This study also identified test order patterns across a spectrum of 20 tests and may be useful for examining the wide variability in test ordering rates between practices. Approaches to ensuring more rational testing may include team work, continuous medical education, guideline dissemination, electronic order systems with decision support, feedback, incentives and audits of family physicians on their request rates and tests costs. We believe that interventions that use multiple educational strategies will be more successful in achieving positive outcomes and providing equitable care.

Acknowledgements Andreia Teixeira thanks to the Fundação para a Ciência e Tecnologiafor the Post-Doctoral Scholarship (SFRH/BPD/863/2012), funded by funds from the Ministério daCiência, Tecnologia e Ensino Superior and bythe Fundo Social by POCH - Programa Operacional Capital Humano.

Contributors LS and CM had the original idea for this study. LS and CM designed the methodology. LS and FT conducted the acquisition data. LS, ASCT, CC-S and 
$\mathrm{CM}$ performed the statistical data analysis and the interpretation of data for the work. LS and CM drafted the paper. LS, CM, ASCT, CC-S, FT, PS, LC, AC-P and APH contributed to the paper design, revised the paper, approved the version to be published and gave their agreement to be responsible for all aspects of the paper. Competing interests None declared.

Ethics approval Northern Regional Health Administration Ethics Committee for Health.

Provenance and peer review Not commissioned; externally peer reviewed.

Data sharing statement № additional data are available.

Open Access This is an Open Access article distributed in accordance with the Creative Commons Attribution Non Commercial (CC BY-NC 4.0) license, which permits others to distribute, remix, adapt, build upon this work non-commercially, and license their derivative works on different terms, provided the original work is properly cited and the use is non-commercial. See: http://creativecommons.org/ licenses/by-nc/4.0/

(C) Article author(s) (or their employer(s) unless otherwise stated in the text of the article) 2017. All rights reserved. No commercial use is permitted unless otherwise expressly granted.

\section{REFERENCES}

1. Leurquin P, Van Casteren V, De Maeseneer J. Use of blood tests in general practice: a collaborative study in eight european countries. Eurosentinel study group. Br J Gen Pract 1995;45:21-5.

2. Royal Australian College of General Practitioners, National Preventive and Community Medicine Committee. Guidelines for preventive activities in general practice. Aust Fam Physician 2012.

3. Martins C, Azevedo LF, Ribeiro O, et al. A population-based nationwide cross-sectional study on preventive health services utilization in Portugal--what services (and frequencies) are deemed necessary by patients? PLoS One 2013;8:e81256.

4. Moynihan R, Doran E, Henry D. Disease mongering is now part of the global health debate. PLoS Med 2008;5:e106.

5. Oraganization for Economic Co-Operation and Development. Health status. https://stats.oecd.org/index.aspx?queryid=24879 (accessed 23 May 2016).

6. Santos P, Nazaré I, Martins C, et al. [The portuguese guidelines and patients values]. Acta Med Port 2015;28:754-9.

7. ACSS. Activity report 2009/2010. Sector agreed. Functional unit contractualisation and financing. $2011 \mathrm{http}: / /$ www2.acss.min-saude. $\mathrm{pt}$

8. Moynihan R, Doust J, Henry D. Preventing overdiagnosis: how to stop harming the healthy. BMJ 2012;344:e3502.

9. Heath I. Overdiagnosis: when good intentions meet vested interests-an essay by lona Heath. BMJ 2013;347:f6361.

10. Salloum S, Franssen E. Laboratory investigations in general practice. Can Fam Physician 1993;39:1055-61.

11. Whiting $P$, Toerien $M$, de Salis I, et al. A review identifies and classifies reasons for ordering diagnostic tests. J Clin Epidemiol 2007:60:981-9.

12. Verstappen WH, ter Riet G, Dubois WI, et al. Variation in test ordering behaviour of GPs: professional or context-related factors? Fam Pract 2004;21:387-95.

13. Smellie WS, Galloway MJ, Chinn D, et al. Is clinical practice variability the major reason for differences in pathology requesting patterns in general practice? J Clin Pathol 2002;55:312-4.

14. Mogyorósy Z, Mogyorósy G. [Practice pattern and geographic variation in test ordering. A literature review]. Orv Hetil 2006;147:25-31.

15. Salinas M, López-Garrigós M, Díaz J, et al. Regional variations in test requiring patterns of general practitioners in Spain. Ups J Med Sci 2011;116:247-51.

16. OECD. Oecd reviews of health care quality: Portugal 2015 - raising standards en oecd. 2016 http://www.oecd.org/publications/oecdreviews-of-health-care-quality-portugal-2015-9789264225985-en. $\mathrm{htm}$ (accessed 2 May 2016).

17. Mindemark $M$, Wernroth $L$, Larsson $A$. Costly regional variations in primary health care test utilization in Sweden. Scand J Clin Lab Invest 2010;70:164-70.

18. Busby J, Schroeder K, Woltersdorf W, et al. Temporal growth and geographic variation in the use of laboratory tests by NHS general practices: using routine data to identify research priorities. Br J Gen Pract 2013;63:256-66.

19. ARS Norte. Northern regional health administrations - SIARS - user manual - functional units. http://portal.arsnorte.min-saude.pt/portal/
page/portal/ARSNorte/Documentos/Manuais/ (accessed 13 Feb 2017).

20. National Institute of Statistics Portal. Projections of resident population 2012-2016. http://www.ine.pt/xportal/xmain? $x p i d=$ INE\&xpgid=ine_destaques\&DESTAQUESdest_boui=208819970\& DESTAQUESmodo=2 (accessed 1 Feb 2015).

21. National Institute of Statistics Portal. Consultative group for the reform of primary health care reform report. Extraordinary even. 2009 https://www.sns.gov.pt/wp-content/uploads/2016/01/ ACONTECIMENTO-EXTRAORDINA\%CC\%81RIO-Relato\%CC\% 81rio-GCRCSP-Fev-2009.pdf (accessed 1 may 2016).

22. Sá L, Ribeiro O, Azevedo LF, et al. Patients' estimations of the importance of preventive health services: a nationwide, populationbased cross-sectional study in Portugal. BMJ Open 2016;6:e011755.

23. Martins CM, da Costa Teixeira AS, de Azevedo LF, et al. The effect of a test ordering software intervention on the prescription of unnecessary laboratory tests - a randomized controlled trial. BMC Med Inform Decis Mak 2017;17:20.

24. Winkens RA, Pop P, Grol RP, et al. Effect of feedback on test ordering behaviour of general practitioners. BMJ 1992;304:1093-6.

25. O'Kane MJ, Casey L, Lynch PL, et al. Clinical outcome indicators, disease prevalence and test request variability in primary care. Ann Clin Biochem 2011;48(Pt 2):155-8.

26. Sood R, Sood A, Ghosh AK. Non-evidence-based variables affecting physicians' test-ordering tendencies: a systematic review. Neth $J$ Med 2007;65:167-77.

27. European forum for primary care. Primary care in Portugal. http:// www.euprimarycare.org/column/primary-care-portugal-0 (accessed 12 Feb 2017).

28. Gill PS, Mäkelä M, Vermeulen KM, et al. Changing doctor prescribing behaviour. Pharm World Sci 1999;21:158-67.

29. von Ferber L, Bausch J, Köster I, et al. Pharmacotherapeutic circles. Results of an 18-month peer-review prescribing-improvement programme for general practitioners. Pharmacoeconomics 1999;16:273-83.

30. Long MJ, Cummings KM, Frisof KB. The role of perceived price in physicians' demand for diagnostic tests. Med Care 1983;21:243-50.

31. Beilby JJ, Silagy CA. Trials of providing costing information to general practitioners: a systematic review. Med J Aust 1997:167:89-92.

32. Ivers N, Jamtvedt G, Flottorp S, et al. Audit and feedback: effects on professional practice and healthcare outcomes. Cochrane Database Syst Rev 2012;6:CD000259.

33. Cummings KM, Frisof KB, Long MJ, et al. The effects of price information on physicians' test-ordering behavior. Ordering of diagnostic tests. Med Care 1982;20:293-301.

34. Tierney WM, Miller ME, McDonald CJ. The effect on test ordering of informing physicians of the charges for outpatient diagnostic tests. $N$ Engl J Med 1990;322:1499-504.

35. Pugh JA, Frazier LM, DeLong E, et al. Effect of daily charge feedback on inpatient charges and physician knowledge and behavior. Arch Intern Med 1989;149:426-9.

36. Sá L, Costa-Santos C, Teixeira A, et al. Portuguese family physicians' awareness of diagnostic and laboratory test costs: a cross-sectional study. PLoS One 2015;10:e0137025.

37. General Direction of Health. Prescription and determination of the hemogram. http://www.dgs.pt (accessed 12 Feb 2017).

38. General Direction of Health. Prescription of laboratory tests for evaluation and monitoring of thyroid function. https://www.dgs.pt (accessed 12 Feb 2017).

39. General Direction of Health. Urinary tract infection therapy (community). https://www.dgs.pt (accessed 12 Feb 2017).

40. van den Brandhof WE, Bartelds Al, Koopmans MP, et al. General practitioner practices in requesting laboratory tests for patients with gastroenteritis in the Netherlands, 2001-2002. BMC Fam Pract 2006;7:56.

41. Vinker S, Kvint I, Erez R, et al. Effect of the characteristics of family physicians on their utilisation of laboratory tests. Br J Gen Pract 2007:57:377-82.

42. Stahl JE, Drew MA, Weilburg J, et al. Face time versus test ordering: is there a trade-off? Am J Manag Care 2013;19:SP362-8.

43. Grytten J, Sørensen R. Practice variation and physician-specific effects. J Health Econ 2003;22:403-18.

44. General Direction of Health. Prescription and determination of glycated hemoglobin A1c. http://www.dgs.pt (accessed 12 Feb 2017).

45. General Direction of Health. Diagnosis and classification of diabetes mellitus. http://www.dgs.pt (accessed 12 Feb 2017).

46. Pysher TJ, Bach PR, Lowichik A, et al. Chemistry test ordering patterns after elimination of predefined multitest chemistry panels in a children's hospital. Pediatr Dev Pathol 1999;2:446-53. 